
9

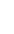

\title{
Biogenic volatile organic compound emissions from senescent maize leaves and a comparison with other leaf developmental stages
}

\author{
A. Mozaffara,b, N. Schoon ${ }^{b}$, A. Bachy', A. Digrado ${ }^{c}$, B. Heinesch ${ }^{a}$, M. Aubineta, M.-L. \\ Fauconniera, P. Delaplace ${ }^{c}$, P. du Jardinc and C. Amelynck ${ }^{\text {b,d }}$ \\ a TERRA Research Center, University of Liege, Gembloux Agro-Bio Tech, 8 Avenue de la \\ Faculté, B-5030, Gembloux, Belgium \\ ${ }^{\mathrm{b}}$ Royal Belgian Institute for Space Aeronomy, Ringlaan 3, B-1180, Brussels, Belgium \\ ${ }^{c}$ Plant Biology Laboratory, AGRO-BIO-CHEM Research Unit, University of Liege, Gembloux \\ Agro-Bio Tech, 2 Passage des Déportés, B-5030, Gembloux, Belgium \\ ${ }^{d}$ Department of Analytical Chemistry, Ghent University, Krijgslaan 281-S12, B-9000, Ghent, \\ Belgium
}

Correspondence to: C. Amelynck (crist.amelynck@aeronomie.be)

Keywords: Leaf senescence; maize; BVOC; GLV; PTR-MS; methanol 


\section{Abstract}

Plants are the major source of Biogenic Volatile Organic Compounds (BVOCs) which have a large influence on atmospheric chemistry and the climate system. Therefore, understanding of BVOC emissions from all abundant plant species at all developmental stages is very important. Nevertheless, investigations on BVOC emissions from even the most widespread agricultural crop species are rare and mainly confined to the healthy green leaves. Senescent leaves of grain crop species could be an important source of BVOCs as almost all the leaves senesce on the field before being harvested. For these reasons, BVOC emission measurements have been performed on maize (Zea mays L.), one of the most cultivated crop species in the world, at all the leaf developmental stages. The measurements were performed in controlled environmental conditions using dynamic enclosures and proton transfer reaction mass spectrometry (PTR-MS). The main compounds emitted by senescent maize leaves were methanol (31\% of the total cumulative BVOC emission on a mass of compound basis) and acetic acid (30\%), followed by acetaldehyde (11\%), hexenals (9\%) and m/z 59 compounds (acetone/propanal) (7\%). Important differences were observed in the temporal emission profiles of the compounds, and both yellow leaves during chlorosis and dry brown leaves after chlorosis were identified as important senescencerelated BVOC sources. Total cumulative BVOC emissions from senescent maize leaves were found to be among the highest for senescent Poaceae plant species. BVOC emission rates varied strongly among the different leaf developmental stages, and senescent leaves showed a larger diversity of emitted compounds than leaves at earlier stages. Methanol was the compound with the highest emissions for all the leaf developmental stages and the contribution from the younggrowing, mature, and senescent stages to the total methanol emission by a typical maize leaf was 61,13 , and $26 \%$, respectively. This study shows that BVOC emissions from senescent maize leaves cannot be neglected and further investigations in field conditions are recommended to further constrain the BVOC emissions from this important $\mathrm{C} 4$ crop species. 


\section{Introduction}

Terrestrial vegetation is a huge source of volatile organic compounds (VOCs) in the Earth's atmosphere. Besides playing a role in plant biology and ecology (Pierik et al., 2014), biogenic VOCs (BVOCs) are generally highly reactive with the major atmospheric oxidants, thus affecting the oxidation capacity of the atmosphere, air quality and climate (Atkinson, 2000; Laothawornkitkul et al., 2009; Pacifico et al., 2009). BVOC emissions from plants are highly species-specific and not only depend on environmental conditions (Guenther et al., 2012) and abiotic or biotic stress factors (Holopainen et al., 2010) but also on plant ontogeny (BrachoNunez et al., 2011). Therefore they should be investigated at all developmental stages, including senescence.

Leaf senescence is the final stage of leaf development. It is a complex energy-dependent selfdigesting process that facilitates the remobilisation of nutrients from the senescing leaf to growing vegetative plant organs or developing seeds and fruits, where they are reused for biosynthesis (Woo et al., 2013; Keskitalo, 2005; Gan and Amasino, 1997; Taiz et al., 2015). Under normal growing conditions leaf senescence is governed by the developmental age of the leaves, which is a function of hormones and other regulatory factors (Taiz et al., 2015). Under unfavourable environmental conditions (e.g. drought or enhanced ozone concentrations) or biotic stress (e.g. pathogen infestation), however, the leaf senescence process can occur prematurely. Three main phases are generally distinguished in the developmental leaf senescence process (Taiz et al., 2015). The initiation phase is characterised by a gradual decline in photosynthesis and a transition of the leaf from being a nitrogen sink to a nitrogen source. Self-digestion of cellular constituents and macromolecules mainly occurs during the second phase, the degenerative phase. The third phase, the terminal phase, is characterised by loss of cellular integrity, cell death, and finally (in most cases) leaf abscission.

Although numerous studies have already been performed on BVOC emissions from healthy and growing leaves where cells were developing (Kuhn et al., 2002; Harley et al., 2007; Hüve et al., 2007; Folkers et al., 2008; Bracho-Nunez et al., 2011; Mozaffar et al., 2017), studies on senescent leaves where cells are breaking down (Gan and Amasino, 1997) are very rare. As far 
as we know, there is only one leaf-scale study, performed under controlled conditions (Holopainen et al., 2010), in which VOC emissions from undetached senescent leaves (of Betula pendula Roth) have been measured, but the measurement frequency was too low (1 Gas Chromatography - Mass Spectrometry (GC-MS) sample every 3 days) to adequately represent the emission dynamics. Therefore, additional studies at increased time resolution are required for a better characterisation of BVOC exchanges between senescent leaves and the atmosphere during the whole senescence period.

To assess the importance of BVOC emission rates from the senescent leaves of a plant, information about BVOC emission rates from other leaf developmental stages (young, semimature, mature) is also necessary. In this study we will mainly focus on BVOC emissions from senescent maize (Zea Mays L.) leaves, but we will also compare them with BVOC emissions from other developmental stages of maize leaves measured under the same environmental conditions. Despite being a vastly cultivated crop species worldwide, only a few literature studies have been devoted to BVOC emissions for this species (MacDonald and Fall, 1993; Das et al., 2003; Graus et al., 2013; Bachy et al., 2016; Mozaffar et al., 2017) and none of them cover all the leaf developmental stages. In particular, data on BVOC emission rates from senescent maize leaves are missing in the abovementioned literature.

Maize is a monocarpic (a plant which only flowers and bears fruit once in its lifetime) herbaceous $\mathrm{C} 4$ plant for which whole plant senescence occurs with seed maturation (Lim et al., 2007). However, the first leaf at the base of the plant starts senescing long before flowering and this process continues for all the leaves from the base to the top of the plant throughout the growing season. Therefore, emissions from senescent leaves could provide a significant contribution to the total BVOC emission budget from a maize field, as suggested by de Gouw et al. (2000).

In order to improve the knowledge on BVOC emissions from this important crop species we aim to provide answers to the following specific questions: 1) which BVOCs are emitted during the senescence process and in what proportions, 2) how do BVOC emissions from senescent maize leaves compare to those from other species of the Poaceae family, 3) how do BVOC emission rates vary among the different leaf developmental stages of maize, and 4) what are the 
contributions of the different developmental stages to the total emission of individual BVOC compounds by a maize leaf/plant.

\section{Materials and methods}

\subsection{Plants and environmental conditions}

The experiments were performed on maize leaves (Zea mays L., variety Prosil, Caussade Semences, France) at four different leaf developmental stages: young, semi-mature, mature, and senescent. To measure BVOC exchanges between young leaves and the atmosphere, 8 to 14 day old maize plants (age counting began at seed germination) were used. The shoots of the young maize plants were completely enclosed because it was not feasible to enclose a single young leaf for a sufficiently long period without damaging it due to the fast elongation rate of both leaves and stem. The upper part (ca. $55 \mathrm{~cm}$ starting from the tip) of almost fully developed, healthy $7^{\text {th }}$ leaves of 30-40 day old plants (around $120 \mathrm{~cm}$ tall) and the fully developed $\left(7^{\text {th }}, 8^{\text {th }}\right.$ or $\left.9^{\text {th }}\right)$ leaves of 60-70 day old, fully grown plants (around $180 \mathrm{~cm}$ tall) were enclosed to measure BVOC emission rates from semi-mature and mature leaves during 5 consecutive days, respectively. The above-mentioned leaf numbers refer to the order in which new leaves appear during plant development and leaf numbering thus starts from the base. The choice for (mainly) $7^{\text {th }}$ leaves was determined by their position with respect to the ground and the ceiling level of the environmental chamber and the possibility to enclose them without damaging them. Senescenceinduced BVOC emission rates were measured from senescing $\left(7^{\text {th }}, 8^{\text {th }}\right.$ or $\left.10^{\text {th }}\right)$ leaves of fully grown 60-95 day old plants. The upper half of those leaves was enclosed a few days before the start of the senescence initiation phase, which was identified by a decrease of photosynthesis (Taiz et al., 2015) and preceded chlorosis, i.e. leaf yellowing due to chlorophyll degradation, by a few days. Chlorosis started at the tip of the leaf and gradually progressed towards the base of the enclosed leaf within 5-10 days (range for 10 replicates). The onset and evolution of leaf chlorosis, however, could only be determined visually and not by a quantitative metric (e.g. photochemical efficiency or chlorophyll content). When describing the BVOC emission rate dynamics in Section 3.1, the term "chlorosis period" refers to the period between the first visual signs of yellowing and the total absence of green areas on the enclosed part of the leaf. Whereas 
135

136

137

138

139

140

141

142

143

144

145

146

147

148

149

150

151

152

153

154

155

156

157

158

159

160

161

162

the period between the onset of the decrease of photosynthesis and the onset of chlorosis can be considered as the initiation phase of leaf senescence, the chlorosis period largely coincides with the degenerative phase. The terminal phase can be mainly associated with the post-chlorosis period (from the end of the chlorosis period to the end of the measurements). It is to be noted that the third phase of senescence in maize does not imply leaf abscission. In order to support the description of the temporal evolution of senescence and BVOC emissions in this Section and in subsections 3.1.1 and 3.1.2, daily pictures of a typical senescent leaf (taken at 10 AM every day), along with the temporal evolution of the daily net photosynthesis rate and the methanol and acetic acid daily emission rates are shown in Fig. 1.

Figure 1

Investigations on young, semi-mature, and mature leaves were performed on 5 replicates for each stage, and 10 replicates were used for investigating emissions from senescent leaves. More details about the enclosed leaves at the different leaf developmental stages and the associated plant age and developmental status can be found in Table 1 .

All these experiments were conducted on potted $(20 \mathrm{~L}$ pots filled with a mixture of $75 \%$ silty clay loam soil and $25 \%$ sand) plants in a temperature and light controlled environmental chamber. Details about the environmental chamber can be found in Mozaffar et al. (2017). The soil was fertilised before planting with NPK fertiliser (6-5-5, Substral Nutrimax, Belgium) containing micronutrients $(\mathrm{Cu}, \mathrm{Fe}, \mathrm{Mn}, \mathrm{Mo}, \mathrm{Zn})$. Daytime temperature in the environmental chamber was maintained at $25^{\circ} \mathrm{C}$ throughout the experimental period and during the night the temperature decreased by around $2^{\circ} \mathrm{C}$ due to the absence of a heat source. Seventeen hours of photoperiod at three different PPFD (Photosynthetic Photon Flux Density) values (100, 330 and $600 \mu \mathrm{mol} \mathrm{m} \mathrm{m}^{-2} \mathrm{~s}^{-1}$ ) were alternated with seven hours of darkness (Fig. 2). All the plants were watered regularly to maintain a good soil moisture content (35-40\%, field capacity was $40 \%$ ). 
Table 1: Detailed information about the enclosed leaf/leaves at the different leaf developmental stages, the associated plant age and two useful metrics, BBCH code and AGDD (Accumulated Growing Degree-Days), for the plant developmental stages at which the experiments were carried out. The BBCH code and AGDD are explained in supplement S1.

\begin{tabular}{|c|c|c|c|c|}
\hline $\begin{array}{l}\text { Leaf developmental } \\
\text { stage }\end{array}$ & $\begin{array}{l}\text { Enclosed } \\
\text { leaf/leaves }\end{array}$ & $\begin{array}{c}\text { Plant age } \\
\text { [days] }\end{array}$ & $\begin{array}{l}\mathrm{BBCH} \\
\text { code }^{*}\end{array}$ & $\begin{array}{c}\text { AGDD } \\
\text { [degree-days] }\end{array}$ \\
\hline Young & first 2-5 leaves & $4-14$ & $10-14$ & $122-274$ \\
\hline $\begin{array}{c}\text { Semi-mature } \\
\text { (almost fully grown) }\end{array}$ & 7 th leaf & $30-40$ & $17-19$ & $518-671$ \\
\hline $\begin{array}{c}\text { Mature } \\
\text { (fully grown) }\end{array}$ & 7th/8th/9th leaf & $60-70$ & $65-69$ & $976-1128$ \\
\hline Senescent & $7 \mathrm{th} / 8 \mathrm{th} / 10^{\text {th }}$ leaf & $60-95$ & $65-69^{*}$ & $976-1510$ \\
\hline
\end{tabular}

\subsection{Experimental setup}

Young maize shoots were enclosed in $22 \mathrm{~L}$ cylindrical dynamic flow-through enclosures made of transparent PFA (perfluoroalkoxy Teflon) envelope (Norton, Saint-Gobain Performance Plastics, NJ, USA). Similar $30 \mathrm{~L}$ enclosures were used to partially enclose the semi-mature, mature, and senescent leaves. In addition, a similar empty enclosure was used to measure the background VOC concentrations in the air that was supplied to the enclosures. The enclosures were equipped with a Teflon fan, a thermistor (type 10k, NTC, Omega, UK), and a relative humidity sensor (type HIH-3610, Honeywell, NJ, USA ) for proper mixing of air and continuous monitoring of leaf temperature, air temperature and relative humidity, respectively. Relative humidity and $\mathrm{CO}_{2}$ concentration in the 5 SLM (standard litre per minute) air flow sent through each of the enclosures were controlled at around $40 \%$ and $400 \mathrm{ppm}$, respectively. A conventional highsensitivity quadrupole-based Proton Transfer Reaction-Mass Spectrometry instrument (hs-PTR- 
MS, Ionicon Analytik GmbH, Innsbruck, Austria) and a LI-7000 non-dispersive IR gas analyser (LI-COR, Lincoln, Nebraska, USA) were used to determine BVOC, $\mathrm{H}_{2} \mathrm{O}$ and $\mathrm{CO}_{2}$ concentrations. In general, BVOC and $\mathrm{H}_{2} \mathrm{O}$ calibrations were performed every 3-5 days and $\mathrm{CO}_{2}$ calibrations were performed monthly. Further details about the set-up have been presented in Mozaffar et al. (2017).

\subsection{Tentative identification and quantification of emitted BVOCs}

The operating principle and technical details of the PTR-MS technique have been amply described in the literature (e.g. Lindinger et al., 1998; Ellis and Mayhew, 2013). In the present work, the quadrupole-based hs-PTR-MS instrument was operated at a drift tube pressure and temperature of $2.1 \mathrm{hPa}$ and $333 \mathrm{~K}$, respectively, and at an $\mathrm{E} / \mathrm{N}$ value (ratio of the electric field to the air number density in the drift tube) of $130 \mathrm{Td}\left(1 \mathrm{Td}=10^{-17} \mathrm{~V} \mathrm{~cm}^{2}\right)$. Measurements were carried out in the Multiple Ion Detection mode, in which the instrument continuously cycled through a list of preset $\mathrm{m} / \mathrm{z}$ values of BVOC-related ion species for which signal intensities above the detection limit have been observed in PTR-MS spectra of maize leaf emissions. The $\mathrm{m} / \mathrm{z}$ values of ions which were used for emission rate quantification, along with a tentative identification of the associated BVOCs are shown in Table 2. This identification mainly relies on Karl et al. (2005) who unambiguously identified BVOCs released from drying rice (O. sativa) by using the hyphenated GC/PTR-MS technique. In addition to the BVOC-related ions, isotopes of the reactant ion species $\mathrm{H}_{3} \mathrm{O}^{+}$(at $\mathrm{m} / \mathrm{z}$ 21) and its first hydrate $\mathrm{H}_{3} \mathrm{O}^{+} \cdot \mathrm{H}_{2} \mathrm{O}$ (at $\mathrm{m} / \mathrm{z}$ 39) were monitored.

\section{(1)}


Table 2: The $\mathrm{m} / \mathrm{z}$ ratios and list of potential contributory compounds for which emission rates were quantified. Compounds that were present in the multi-component calibration bottles are indicated in bold and their mixing ratios ( $\pm 5 \%$ accuracy) in the bottles are also shown.

\begin{tabular}{|c|c|c|c|}
\hline \multirow[t]{2}{*}{$\mathrm{m} / \mathrm{z}$} & \multirow[t]{2}{*}{ Compound } & \multicolumn{2}{|c|}{ Mixing ratio (ppbv) } \\
\hline & & Bottle $1^{\mathrm{a}}$ & Bottle $2^{\mathrm{a}}$ \\
\hline 33 & Methanol & 1074 & 1013 \\
\hline 45 & Acetaldehyde & 999 & 969 \\
\hline 57 & Hexenals & & $1041^{\mathrm{b}}$ \\
\hline 59 & Acetone, propanal, 2,3-butanedione & 973 & 502 \\
\hline 61 & Acetic acid & & \\
\hline 69 & Isoprene, pentenol, n-pentanal & 441 & 483 \\
\hline 73 & $\begin{array}{l}\text { Methyl ethyl ketone (MEK), 2-methyl-propanal, } \\
\text { butanal }\end{array}$ & 494 & 516 \\
\hline \multirow[t]{2}{*}{81} & Monoterpenes, & $851^{\mathrm{c}}$ & \\
\hline & Hexenals & & $1041^{\mathrm{b}}$ \\
\hline 83 & Hexenols, n-hexanal, hexenyl acetates & & $986^{\mathrm{d}}$ \\
\hline 99 & Hexenals & & $1041^{\mathrm{b}}$ \\
\hline 137 & Monoterpenes & $851^{\mathrm{c}}$ & \\
\hline
\end{tabular}

211

$212{ }^{\text {a }}$ Calibration bottle 1 was used for the experiments with young, semi-mature and mature leaves.

213 Bottle 2 was used for the senescence experiments.

$214^{b}$ Trans-2-hexenal was used as a proxy for hexenals and was the only compound in calibration bottle 2 which resulted in product ions at $\mathrm{m} / \mathrm{z} 81$.

${ }^{c}$ Alpha-pinene (452 ppbv) and sabinene (399 ppbv) were used as proxies for the monoterpene 217 family and were the only compounds in calibration bottle 1 which resulted in product ions at $\mathrm{m} / \mathrm{z}$ 21881.

${ }^{\mathrm{d}}$ Only the cis-3-hexenol isomer was present in the calibration bottle 
PTR-MS calibrations were performed by using two gravimetrically prepared multi-component mixtures of BVOCs in nitrogen (Apel-Riemer Environmental Inc., Denver, CO, USA) with a certified accuracy of 5\%. The calibration gas was further diluted with zero air, generated by sending ambient air through a catalytic converter (Parker® ChromGas ${ }^{\circledR}$ Zero Air Generator, model 1001, Parker Hannifin Corporation, Haverhill, MA, USA), to obtain mixing ratios in the lower ppbv range. When several compounds potentially contributed to the ion signal at a given nominal $\mathrm{m} / \mathrm{z}$ value (e.g. methyl ethyl ketone, 2-methyl-propanal and butanal at $\mathrm{m} / \mathrm{z} 73$ ), it was assumed that they possessed similar calibration factors. By calibrating the PTR-MS to the compound indicated in bold in Table 2 (methyl ethyl ketone for the above-mentioned example) and applying the calibration factor to the measured ion signal at that $\mathrm{m} / \mathrm{z}$, we estimated the sum of the concentrations of those compounds.

The $\mathrm{H}_{3} \mathrm{O}^{+} /$monoterpene reaction in the drift tube reactor of the PTR-MS is known to result mainly in the protonated molecule at $\mathrm{m} / \mathrm{z} 137$ and a fragment at $\mathrm{m} / \mathrm{z} 81$ and the product ion distribution is isomer-dependent (Tani et al., 2003). However, since the rate constant for proton transfer from $\mathrm{H}_{3} \mathrm{O}^{+}$to monoterpenes is isomer-independent, the sum of the ion signals at $\mathrm{m} / \mathrm{z} 81$ and 137, weighted for their relative transmission in the mass spectrometer, is expected to be isomer-independent. This sum was used to determine the emission rate of all monoterpene isomers emitted by the young, semi-mature, and mature leaves. During the measurements with senescent leaves the ion signals at $\mathrm{m} / \mathrm{z} 137$ were always below the detection limit, even when ion signals at $\mathrm{m} / \mathrm{z} 81$ were maximal $\left(\mathrm{I}_{137} / \mathrm{I}_{81}\right.$ at maximum $\mathrm{I}_{81}$ is $0.01 \pm 0.02$ with $\mathrm{I}_{137(81)}$ being the net ion signal at $\mathrm{m} / \mathrm{z}$ 137(81)). This indicates that monoterpene emission rates were not significant during this stage and that ions at $\mathrm{m} / \mathrm{z} 81$ did not result from dissociative proton transfer of monoterpenes but corresponded to dehydrated protonated hexenals. In order to obtain accurate emission rates for the sum of hexenal isomers, the other main proton transfer product ions of hexenals at m/z 57 and m/z 99 (Pang, 2015) were also continuously monitored, both during the enclosure measurements and calibrations, and the sum of the signals of the three product ion species, weighted for ion transmission in the mass spectrometer, was used to derive the emission rate of the sum of hexenal isomers. As hexenals and monoterpenes both result in a product ion at $\mathrm{m} / \mathrm{z}$ 81, calibration of the PTR-MS for those compounds required the use of two multicomponent calibration mixtures containing either a hexenal or a monoterpene, in addition to the 
251

252

253

254

255

256

257

258

259

260

261

262

263

264

265

266

267

268

269

270

271

272

273

274

275

276

other compounds to be quantified (Table 2). The calibration mixture containing the monoterpenes was used for the experiments on young, mature, and semi-mature leaves, whereas the mixture containing hexenal was used for the experiments on senescent leaves.

The calibration factor for acetic acid (at $\mathrm{m} / \mathrm{z} 61$ ), a compound which was not present in the calibration bottles, was estimated from the factor for acetone (at $\mathrm{m} / \mathrm{z} 59$ ) by considering the fragmentation of the protonated molecules in the drift tube (Inomata and Tanimoto, 2010; Schwarz et al., 2009) and the ratio of the calculated collision rate constants for the proton transfer reactions ( $\mathrm{Su}, 1994)$, and by assuming the same PTR-MS transmission efficiency for ions at $\mathrm{m} / \mathrm{z} 59$ and 61 . The $\mathrm{m} / \mathrm{z} 81$ and 83 compounds emitted by the senescent leaves are associated to C6 volatiles (hexenals, hexanal, hexenols, hexenyl acetates) and will be designated as green leaf volatiles (GLVs) hereafter.

\subsection{Emission rate computation}

Unless explicitly mentioned otherwise, BVOC emission rates $\mathrm{E}_{\mathrm{BVOC}}$ from maize leaves are expressed as mass flow rates per unit of leaf dry weight $\left[\mu \mathrm{g}\right.$ of the compound $\left.\mathrm{g}_{\mathrm{DW}}{ }^{-1} \mathrm{~s}^{-1}\right]$. They are calculated according to Eq. 1 in which $F_{\text {air }}$ is the molar flow rate of the air which is supplied to the enclosure, $\mathrm{M}_{\mathrm{BVOC}}$ is the molar mass of the BVOC, DW is the dry weight of the enclosed (part of the) leaf, and $\mathrm{x}_{\mathrm{BVOC}, \mathrm{PE}}$ and $\mathrm{x}_{\mathrm{BVOC}, \mathrm{RE}}$ are the mole fractions of the BVOC in the sampled air from the plant enclosure and the empty reference enclosure, respectively.

$$
E_{B V O C}=\frac{F_{a i r} \times\left(x_{B V O C, P E}-x_{B V O C, R E}\right) \times M_{B V O C}}{D W}
$$

The mole fractions of the BVOC are obtained by dividing the normalised background-corrected PTR-MS BVOC ion signals $\mathrm{I}_{\mathrm{m} / \mathrm{z}}$, expressed in normalised counts per second (ncps), by the BVOC calibration coefficients $C_{B V O C}\left[\right.$ ncps ppbv $^{-1}$ ] (Mozaffar et al., 2017).

The dry weight of the leaves was determined at the end of the experiments after at least 48 hours of drying in an oven at $75^{\circ} \mathrm{C}$ until all water was evaporated and a constant weight was reached. Photosynthesis and transpiration rates were obtained in a similar way but are expressed in molar units and per unit of leaf area $\left[\mathrm{mol} \mathrm{m}^{-2} \mathrm{~s}^{-1}\right]$. Leaf area was estimated as described in Mozaffar et al. (2017). 


\section{Results and discussion}

279

280

281

282

283

284

285

286

287

288

289

290

291

292

293

294

295

296

297

\subsection{BVOC emissions from senescent maize leaves}

Significant emissions of methanol, acetaldehyde, m/z 59 compounds, acetic acid, and hexenals were observed from senescent maize leaves and their temporal evolution is shown in Fig. 2 for a single leaf.

Figure 2

Although the plants were grown and investigated under the same environmental conditions, a considerable variability was noticed in the temporal evolution of the emissions among the different replicates as is shown in Figures S1a and S1b in Supplement S1. However, the BVOC emission dynamics from the investigated leaves show similar characteristics, as will be described in the following subsections. Small emission rates of $\mathrm{m} / \mathrm{z} 69, \mathrm{~m} / \mathrm{z} 73$ and $\mathrm{m} / \mathrm{z} 83$ compounds were also noticed (Table 3), but they often barely exceeded the detection limit. The emergence of BVOC emissions or their increase (in case the BVOC was also emitted constitutively) took place at the start of the degeneration phase. Photosynthesis and transpiration diminished gradually as chlorosis progressed from the apex towards the base of the leaf and finally stopped 2-4 days before the end of the chlorosis period (as shown in Fig. 2 for one replicate). While some of the BVOCs were predominantly emitted during and just after the degeneration phase, others were emitted during the termination phase of senescence as well, as will be discussed in detail in the following sections.

The temporal emission dynamics of the individual BVOC species, the relative contribution of their cumulative emissions to the total emission, as well as a comparison with cumulative emissions for other senescent species of the Poaceae family will be discussed hereafter. 
302

303

304

305

306

307

308

309

310

311

312

313

314

315

316

317

318

319

320

321

322

323

324

325

326

327

328

329

330

3.1.1 Methanol, acetaldehyde and GLVs are predominantly emitted during the degeneration phase of leaf senescence

At the beginning of the chlorosis period, the emission rates of methanol, acetaldehyde, and hexenals rose slowly as leaf discoloration moved from the tip to the base and they increased faster when the leaf was turning brown and was shrinking due to the drying process. The highest emission rates occurred at around 1-3, 0-2 and 0-2 days before the end of the chlorosis period, respectively (Fig. 2 and Fig. S1a). By then photosynthesis and transpiration from the steadily decreasing green part of the enclosed leaf were already greatly reduced. Emissions of methanol, acetaldehyde, and hexenals exceeding $20 \%$ of their maximum value lasted for 3-8, 3-7, and 2-7 days, respectively. The temporal evolution of normalised $\mathrm{m} / \mathrm{z} 83$ compound emission rates was similar to that of normalised hexenal emission rates (data not shown). The variability in the duration of the high emission periods for the different compounds reflects the variability in temporal emission profiles for the 10 replicates (Fig. S1a in Supplement S1) . Figure 2 also shows small methanol and acetaldehyde emissions after the chlorosis period which persisted until the end of the measurements. These emissions showed a fixed diurnal pattern with a maximum emission rate of at most $10 \%$ of the maximum emission rate during the chlorosis period.

As can be seen in Fig. 2 and in Fig. S1a, no distinct diurnal patterns were observed for methanol, acetaldehyde, and GLV emission rates during the chlorosis period and there was no clear correlation between these emission rates and the environmental conditions (temperature, PPFD) in the dynamic enclosures. This is in agreement with previous observations of emissions of these compounds from drying leaves (Fall et al., 1999; Warneke et al., 1999; Warneke et al., 2002).

The link between the evolution of the senescent leaf and the temporal emission profile suggests that the biochemical and physical mechanisms involved in leaf chlorosis and drying are major drivers of BVOC emissions during leaf senescence. Presumably collapse of the cellular structure during drying (Karl et al., 2001a; Karl et al., 2001c; de Gouw et al., 1999) and disintegration of cell organelles and dying cells (Keskitalo et al., 2005) are at the origin of high emissions of these compounds. Ozuna et al. (1985) reported that the stomata of senescent 
331

332

333

334

335

336

337

338

339

340

341

342

343

344

345

346

347

348

349

350

351

352

353

354

355

356

357

358

359

Nicotiana glauca leaves which already showed marked chlorosis (the degree of chlorosis varied from 60 to $90 \%$ of the total leaf surface area) remained closed even in the presence of light. As maximum emissions of methanol and acetaldehyde in our experiments were measured close to the end of the chlorosis period, the main emission route for those compounds during the degeneration phase of leaf senescence was therefore probably no longer diffusion through the stomata, as is the case for healthy leaves (MacDonald and Fall, 1993; Kreuzwieser et al., 2000; Rottenberger et al., 2004). As changes in the biomechanical properties of the epidermis cuticle have been reported for Sonneratia alba leaves (Takahashi et al., 2012) during this senescence phase, diffusion of those compounds through a degraded epidermal layer might be considered as a potential emission route.

In leaves, methanol is mainly produced by pectin demethylation in the cell wall, catalysed by pectin methylesterase (PME) enzymes (Fall and Benson, 1996; Fall 2003). This process occurs during growth as well as during aging and senescence of plant tissues (Nemecek-Marshall et al., 1995). Due to continuous breakdown of cellular materials for nutrient remobilisation during the degeneration phase of senescence (Woo et al., 2013; Keskitalo, 2005), massive changes occur in the primary cell wall structure, which potentially stimulates massive methanol production. Methanol emissions from the dead, brown leaves during the termination phase could be either due to the physical membranes breakdown following dehydration or result from the presence of active PME in dead plant materials (Castaldo et al., 1997; Galbally and Kirstine, 2002). Indeed, most of the PME formed by the plant remains active under normal environmental conditions and is capable of demethylation of about $65 \%$ of the pectin in the dead plant material (Galbally and Kirstine, 2002).

The acetaldehyde production mechanism in senescent leaves is not yet well known, but fatty acid peroxidation by reactive oxygen species (ROS) has been suggested by Jardine et al. (2009) as a potential mechanism based on their ${ }^{13} \mathrm{C}$ isotope analysis studies on stressed leaves of deciduous trees. As increased oxidative stress and lipid peroxidation have been observed (Prochazkova et al., 2001) during maize leaf senescence, the suggested mechanism might be responsible for high production of acetaldehyde during the degeneration phase. 
GLV emissions from senescent leaves have been reported previously in the literature. While Holopainen et al. (2010) mentioned increases in GLV emissions from senescent leaves of Betula pendula Roth before abscission, others observed hexenal and hexenol emissions from leaf drying experiments (Fall et al., 1999; Fall et al., 2001; de Gouw et al., 2000; Karl et al., 2001a; Karl et al., 2001c; Karl et al., 2001b; Warneke et al., 2002; Karl et al., 2005). During leaf senescence, most of the cellular fatty acids are oxidised to supply energy for the senescence process (Lim et al., 2007). Since fatty acid oxidation, catalysed by 13-lipoxygenase (13-LOX), is the initial step in GLV production in leaves (Scala et al., 2013; Hatanaka et al., 1993), high GLV emissions can be expected during leaf senescence. Furthermore, recent research revealed the key role of this enzyme in the degradation of chloroplasts during leaf senescence (Springer et al., 2016), potentially leading to strong increases in the emission of GLVs with increasing chlorosis of the leaf.

\subsubsection{Persistent $\mathrm{m} / \mathrm{z} 59$ compounds and acetic acid emissions during the terminal phase of leaf senescence}

Whereas the temporal evolution of acetic acid emissions was well-marked and no emissions were observed prior to senescence, normalized m/z 59 compounds emissions from senescent leaves showed a much smaller increase with respect to the constitutive emissions by the end of the chlorosis period (Fig. 2 and Fig. S1b). Normalised acetic acid and m/z 59 compounds emissions increased somewhat slower than those of methanol, acetaldehyde and GLVs, resulting in a delay of their maximum emissions with respect to the latter three compounds by 1-2 days.

Furthermore, in strong contrast to methanol, acetaldehyde and GLVs, acetic acid and m/z 59 compounds emission rates remained close to their maximal value for a few days after the end of the chlorosis period and then slowly decreased with time, but never reached zero during the entire measurement period. Early morning acetic acid emissions were generally somewhat lower than at the end of the day, presumably due to a decrease in temperature in the leaf enclosures during the night. A similar diurnal behaviour was observed for the $\mathrm{m} / \mathrm{z} 59$ compounds emissions from senescent leaves which, in contrast to the pre-senescence constitutive emissions, remained well above the zero level in dark conditions. High day and night-time m/z 59 compounds emissions (acetone) from dry plant parts and litter have previously been mentioned in the 
literature (Schade and Goldstein, 2001; Warneke et al., 2002) and acetic acid emissions from dry plant material have been reported as well (Kesselmeier et al., 1998; Warneke et al., 1999; Crespo et al., 2013). The production of acetone and acetic acid during the drying process following the chlorosis period might be explained by the occurrence of a non-enzymatic Maillard reaction (Ikan et al., 1996). After the end of the chlorosis period a significant positive correlation $\left(\mathrm{R}^{2}=\right.$ $0.53, \mathrm{P}<0.01$ ) was observed between the acetic acid emissions and the relative humidity of the air supplied to the enclosures. Similarly, Warneke et al. (1999) observed a large increase in partially oxidised VOC (POVOC) emissions after wetting of dried biomatter. They explained this by the transfer of some of the POVOC molecules, produced by the Maillard reaction and remaining attached to the surface of the solid structure of the dry leaf material, to the aqueous phase through replacement by highly polar water molecules. The dissolved POVOCs were subsequently transferred from the aqueous to the gas phase until a gas/liquid equilibrium, determined by the Henry's law constant, was reached. Although the dry leaves were not wetted in our experiments, release of acetic acid molecules from the biomass surface layer may have been influenced by the presence of a relative humidity dependent microlayer of water on the surface layer or by interactions with polar water vapour molecules. Those interactions may have promoted the release of the polar BVOC molecules from the surface layer. A short additional experiment was carried out in which an inert surface, coated with a pure acetic acid microlayer, was inserted in an empty enclosure demonstrated that such a positive correlation between acetic acid emissions and relative humidity was not restricted to senescent biomass. Indeed, the acetic acid emission rate from the coated surface, which was of similar magnitude to that of the enclosed senescent maize leaves, was found to increase by a factor of 2.7 when increasing the relative humidity of the purge air from 40 to $64 \%$. Moreover, increased emissions of acetic acid and other polar compounds with increasing relative humidity have been reported previously from other materials such as wood boards (Steckel et al., 2013) and indoor furniture (Fechter et al., 2006; Schaeffer et al., 1996). 


\section{3.1.3 Absolute BVOC emissions from senescent maize leaves and relative 416 contribution of the emitted compounds to the total BVOC emission from 417 senescent leaves}

418 Cumulative emissions of the quantified BVOCs for the different senescence phases are shown in 419 Table 3, along with the maximum instantaneous emissions and the maximum daily emissions 420 that have been observed over the entire senescence period. Additional statistical information on 421 instantaneous and daily emissions and on cumulative emissions from the investigated senescent 422 leaves is provided in Table S2 and in Fig. S2 in Supplement S1. The emission rates for some 423 compounds (e.g. methanol, m/z 59 compounds, and acetic acid) were still well above the 424 detection limit at the end of the measurement period. Consequently, the reported cumulative 425 emission values from the onset of senescence to the end of the measurement period (31 days) for 426 those compounds should be considered as lower limits for their total cumulative emissions 427 during leaf senescence. 
Table 3: BVOC emissions from maize leaves at different leaf developmental stages. Maximum values for the instantaneous ( $\left.E_{\text {inst,max }}\right)$ and for the daily emission rate $\left(E_{\text {day,max }}\right)$, and cumulative emissions for the initiation, degeneration, and termination phases are shown for the different BVOCs emitted during senescence. Also tabulated are the daily emission rates $\left(\mathrm{E}_{\text {day }}\right)$ from young, semi-mature and mature maize leaves. Data for the senescent leaves are averages over 10 replicates and data for the young, semi-mature and mature leaves are averages over 5 replicates. The error on the emission rates corresponds to the standard deviation $(1 \sigma)$.

\begin{tabular}{|c|c|c|c|c|c|c|c|c|}
\hline \multirow[b]{3}{*}{ Compounds } & \multirow{3}{*}{$\begin{array}{l}\mathrm{E}_{\text {inst,max }} \\
\left(\mathrm{ng} \mathrm{g}_{\mathrm{DW}}{ }^{-1}\right. \\
\left.\mathrm{s}^{-1}\right)\end{array}$} & \multicolumn{3}{|c|}{ Senescent leaves } & \multirow{3}{*}{$\begin{array}{l}E_{\text {day,max }} \\
\left(\mu g_{D W}{ }^{-1}\right. \\
\left.\text { day }^{-1}\right)\end{array}$} & \multirow{3}{*}{$\begin{array}{l}\quad \begin{array}{l}\text { Young } \\
\text { leaves }\end{array} \\
\mathrm{E}_{\text {day }} \\
\left(\mu \mathrm{g}_{\mathrm{DW}}{ }^{-1}\right. \\
\left.\text { day }^{-1}\right)\end{array}$} & \multirow{3}{*}{\begin{tabular}{l}
\multicolumn{1}{c}{ Semi- } \\
mature \\
leaves \\
$\mathrm{E}_{\text {day }}$ \\
$\left(\mu \mathrm{g}_{\mathrm{DW}}{ }^{-1}\right.$ \\
day $\left.^{-1}\right)$
\end{tabular}} & \multirow{3}{*}{$\begin{array}{l}\quad \begin{array}{l}\text { Mature } \\
\text { leaves }\end{array} \\
\mathrm{E}_{\text {day }} \\
\left(\mu \mathrm{g}_{\mathrm{DW}}{ }^{-1}\right. \\
\left.\text { day }^{-1}\right)\end{array}$} \\
\hline & & \multicolumn{3}{|c|}{$E_{a c c}\left(\mu g g_{D W}{ }^{-1}\right)$} & & & & \\
\hline & & $\begin{array}{l}\text { Initiation } \\
\text { phase }\end{array}$ & $\begin{array}{l}\text { Degeneration } \\
\text { phase }\end{array}$ & $\begin{array}{l}\text { Termination } \\
\text { phase }\end{array}$ & & & & \\
\hline Methanol & $0.9 \pm 0.4$ & $14 \pm 11$ & $150 \pm 30$ & $50 \pm 20$ & $53 \pm 16$ & $137 \pm 17^{*}$ & $4.1 \pm 0.7 *$ & $4.8 \pm 1.0^{*}$ \\
\hline Acetaldehyde & $0.38 \pm 0.10$ & $1 \pm 2$ & $44 \pm 12$ & $32 \pm 19$ & $15 \pm 3$ & - & - & - \\
\hline $\mathrm{m} / \mathrm{z} 59$ compounds & $0.05 \pm 0.02$ & $5 \pm 5$ & $12 \pm 7$ & $31 \pm 20$ & $2.3 \pm 1.2$ & $2.7 \pm 1.1$ & $0.4 \pm 0.2$ & $0.9 \pm 0.3$ \\
\hline Acetic acid & $0.17 \pm 0.05$ & $6 \pm 7$ & $40 \pm 20$ & $160 \pm 60$ & $12 \pm 4$ & $<\mathrm{DL}^{* *}$ & $<\mathrm{DL}$ & $<\mathrm{DL}$ \\
\hline $\mathrm{m} / \mathrm{z} 69$ compounds & $0.08 \pm 0.02$ & $3 \pm 3$ & $13 \pm 8$ & $22 \pm 16$ & $3.4 \pm 1.3$ & $<\mathrm{DL}$ & $<\mathrm{DL}$ & $<\mathrm{DL}$ \\
\hline $\mathrm{m} / \mathrm{z} 73$ compounds & $0.03 \pm 0.02$ & $3 \pm 4$ & $5 \pm 7$ & $11 \pm 15$ & $1.2 \pm 1.3$ & $1.7 \pm 1.0$ & $0.4 \pm 0.2$ & $0.30 \pm 0.08$ \\
\hline Hexenals & $0.21 \pm 0.14$ & $6 \pm 7$ & $30 \pm 20$ & $20 \pm 20$ & $10 \pm 8$ & - & - & - \\
\hline Monoterpenes & $<\mathrm{DL}$ & $<\mathrm{DL}$ & $<\mathrm{DL}$ & $<\mathrm{DL}$ & $<\mathrm{DL}$ & $10 \pm 6$ & $0.6 \pm 0.2$ & $0.4 \pm 0.2$ \\
\hline $\mathrm{m} / \mathrm{z} 83$ compounds & $0.07 \pm 0.02$ & $1.4 \pm 1.7$ & $9 \pm 6$ & $11 \pm 9$ & $2.6 \pm 1.5$ & - & - & - \\
\hline
\end{tabular}


437 Methanol and acetic acid were clearly the compounds with the highest emissions (expressed in 438 mass of compound per leaf dry weight), accounting both for around $30 \%$ of the total cumulative 439 emission from the onset of senescence to the end of the investigations (Fig. 3a). They were 440 followed by acetaldehyde (11\%), hexenals (9\%), m/z 59 compounds (7\%), and m/z 69 441 compounds $(6 \%)$. The $\mathrm{m} / \mathrm{z} 73$ and $\mathrm{m} / \mathrm{z} 83$ compounds also made up a small fraction of the total 442 BVOC emissions from the senescent leaves, but their individual contributions were not higher 443 than $3 \%$.

445 Figure 3

Fig. 3 clearly shows that the relative contribution of the emitted compounds varied among the 448 time periods considered. Differences in relative BVOC composition reflect the differences in 449 temporal emission dynamics among BVOCs that were discussed in Section 3.1.1 and 3.1.2. 450 Indeed, as methanol, acetaldehyde, and hexenals were predominantly emitted during the 451 degeneration phase (see Table 3), it is clear that those compounds together made up a large part $452(75 \%)$ of the BVOC emissions for that period (Fig. 3b). Because of the strong persistence of $\mathrm{m} / \mathrm{z}$ 45359 compounds and acetic acid emissions after the chlorosis period, the relative contribution of 454 those compounds increased with time after that period. During the termination phase (Fig. 3c), 455 the m/z 59 compounds and acetic acid together made up half (55\%) of the BVOC emissions, and acetic acid was predominantly emitted during that period $(46 \%)$.

While some studies (Karl et al., 2001b; Karl et al., 2005; Eller et al., 2011; Crespo et al., 458 2013) have reported cumulative BVOC emissions from biomass drying and simulated 459 drying/senescence experiments, information about cumulative BVOC emissions from senescent 460 leaves that are still attached to the plant is, to our knowledge, not available in the literature. 461 Moreover, the abovementioned studies are the only available ones which report cumulative 462 emissions in conditions which somehow approximate senescence in real natural conditions. 463 Therefore we will compare the cumulative BVOC emissions from senescent maize leaves over 464 the entire measurement period against the results from those studies (Table 4), which were all 465 performed on different species of the Poaceae family. Overall, BVOC emissions from senescent 
466 maize leaves are among the highest for the drying/senescent plant species. The cumulative 467 methanol emission from the senescent maize leaves is very similar to that of hay, reported by 468 Karl et al. (2001b). By contrast, cumulative methanol emissions from Sorghum sudanense 469 (sorghum) (Karl et al., 2005), Oryza sativa (rice) (Karl et al., 2005), Panicum virgatum 470 (switchgrass) (Eller et al., 2011), and Phyllostachys nigra (black bamboo) (Crespo et al., 2013) 471 are several orders of magnitude lower than those for maize and hay. Cumulative emissions of 472 acetaldehyde, $\mathrm{m} / \mathrm{z} 59$, and $\mathrm{m} / \mathrm{z} 69$ compounds from maize are of the same order of magnitude as 473 those from drying hay and black bamboo, and considerably higher than those from sorghum, rice, 474 and switchgrass. Total acetic acid emission from maize is several-fold higher than that of black 475 bamboo, which is the only other species of the Poaceae family for which cumulative acetic acid 476 emissions have been reported (Warneke et al. (1999) also mentioned acetic acid emission from 477 grass, but didn't report cumulative emissions). Maize, hay, rice, and black bamboo all have 478 higher cumulative GLV emissions than sorghum and switchgrass.

479 This comparison of cumulative BVOC emissions from the different plant species should, 480 however, be taken with caution because of differences in the way they have been determined 481 (from leaves still attached to the plant as in this study or from cutting of biomass, followed by 482 drying in the field or in an oven as in the other studies), in environmental conditions during the 483 experiments, and in the length of the accumulation period (see Table 4). 
Table 4: Comparison of the cumulative BVOC emissions during senescence of maize leaves and drying of hay, Sorghum sudanense 485 (sorghum), Oryza sativa (rice), Panicum virgatum (switchgrass) and Phyllostachys nigra (black bamboo). Also mentioned in the 486 Table are the accumulation period and the temperature at which the experiments were performed.

\begin{tabular}{|c|c|c|c|c|c|c|}
\hline & Maize & Hay & Sorghum & Rice & Switchgrass & $\begin{array}{l}\text { Black } \\
\text { bamboo }\end{array}$ \\
\hline & Current study & $\begin{array}{l}\text { Karl et al. } \\
\text { (2001b) }\end{array}$ & \multicolumn{2}{|c|}{$\begin{array}{c}\text { Karl et al. } \\
\text { (2005) }\end{array}$} & $\begin{array}{l}\text { Eller et al. } \\
\text { (2011) }\end{array}$ & $\begin{array}{l}\text { Crespo et al. } \\
(2013)\end{array}$ \\
\hline & $\begin{array}{l} \pm \text { total } \\
(\sim 31 \text { days })\end{array}$ & total & $\begin{array}{l}\text { total } \\
\text { (7-9 hours) }\end{array}$ & $\begin{array}{l}\text { total } \\
\text { (7-9 hours) }\end{array}$ & $\begin{array}{l}\text { partial } \\
\text { (1 day) }\end{array}$ & $\begin{array}{l}\text { total } \\
\text { (3 days) }\end{array}$ \\
\hline & $25^{\circ} \mathrm{C}$ & $25-35^{\circ} \mathrm{C}$ & $30^{\circ} \mathrm{C}$ & $30{ }^{\circ} \mathrm{C}$ & $30^{\circ} \mathrm{C}$ & $80{ }^{\circ} \mathrm{C}$ \\
\hline Compound & $\left(\mu \mathrm{g} / \mathrm{g}_{\mathrm{DW}}\right)$ & $\left(\mu \mathrm{g} / \mathrm{g}_{\mathrm{DW}}\right)$ & $\left(\mu \mathrm{g} / \mathrm{g}_{\mathrm{DW}}\right)$ & $\left(\mu \mathrm{g} / \mathrm{g}_{\mathrm{DW}}\right)$ & $\left(\mu \mathrm{g} / \mathrm{g}_{\mathrm{DW}}\right)$ & $\left(\mu \mathrm{g} / \mathrm{g}_{\mathrm{DW}}\right)$ \\
\hline Methanol & $210 \pm 30$ & 160 & $2 \pm 0.9$ & $3.1 \pm 0.8$ & $9.07 \pm 2.35$ & 26.1 \\
\hline Acetaldehyde & $80 \pm 30$ & $20-80$ & $6.6 \pm 2$ & $8.4 \pm 0.7$ & $13.99 \pm 5.44$ & 73.2 \\
\hline $\mathrm{m} / \mathrm{z} 59$ compounds & $50 \pm 30$ & $20-40$ & $0.4 \pm 0.3$ & $1.7 \pm 1.1$ & $2.21 \pm 0.69$ & 13.3 \\
\hline Acetic acid & $200 \pm 80$ & - & - & - & - & 28.6 \\
\hline $\mathrm{m} / \mathrm{z} 69$ compounds & $40 \pm 20$ & $15^{\mathrm{a}}$ & $0.32 \pm 0.13^{b}$ & $3.2 \pm 1.7^{b}$ & $1.15 \pm 0.53^{\mathrm{c}}$ & $58^{\mathrm{c}}$ \\
\hline $\mathrm{m} / \mathrm{z} 73$ compounds & $20 \pm 30$ & $11-80$ & - & - & - & - \\
\hline Hexenals & $60 \pm 50$ & $100-240$ & $0.53 \pm 0.17$ & $100 \pm 49$ & $1.49 \pm 1.42$ & $231^{\mathrm{d}}$ \\
\hline $\mathrm{m} / \mathrm{z} 83$ compounds & $21 \pm 15$ & $30-60^{\mathrm{e}}$ & $0.36 \pm 20.17$ & $34 \pm 13$ & $1.06 \pm 1.49$ & \\
\hline
\end{tabular}

488 a pentenol and 2-methyl-butanal; ${ }^{\mathrm{b}}$ pentenol and n-pentanal; ${ }^{\mathrm{c}}$ pentenol and isoprene; ${ }^{\mathrm{d}}$ based on the sum of ion intensities at $\mathrm{m} / \mathrm{z} 57$,

$48981,99,83,101$, and $103 ;{ }^{\mathrm{e}}$ hexenols and hexanal 

maize leaf/plant

492 In order to investigate the relative importance of BVOC emission rates from senescent maize 493 leaves, these emission rates were compared with those of young, semi-mature, and mature maize 494 leaves measured under the same environmental conditions (Table 3). Strong variations in daily emission rates were observed among the different leaf developmental stages for those compounds that could be quantified for the three earliest stages. Methanol was clearly the compound with the highest emission rates for all stages. The highest daily emission rate during the senescence period was about $40 \%$ of the average daily emission rate for the young leaves and about a factor of 10 higher than that of semi-mature and mature leaves. The high emission rates for senescent and young leaves with respect to those of the other developmental stages are due to enhanced production of methanol by PME-catalysed demethylation of pectin during cell wall remodelling. Whereas complex diurnal methanol emission profiles were found for the young

503 leaves (Mozaffar et al., 2017), no clear correlation between the methanol emission rate and PPFD 504 could be observed for the senescent leaves either. Maximum daily emission rates for $\mathrm{m} / \mathrm{z} 59$ and $505 \mathrm{~m} / \mathrm{z} 73$ compounds during senescence were of similar magnitude to the corresponding average 506 daily emission rates for young leaves and about 3-6 times higher than the average daily emission 507 rates for the semi-mature and mature leaves. Daily monoterpene emission rates for young maize leaves were more than ten-fold higher than for semi-mature and mature leaves and emission rates from senescent leaves were below the detection limit. Higher acetone and monoterpene emissions from young leaves have previously been reported in the literature and higher defence requirements for the young leaves (Bracho-Nunez et al, 2011) and lower metabolic activity in mature leaves resulting in low de novo synthesis rates (Aalto et al., 2014) have been proposed as potential reasons.

514 Although the data listed in Table 3 allow a comparison between the maximum daily BVOC 515 emission rates during senescence and the average daily BVOC emission rates measured during 516 relatively short periods for the young, semi-mature, and mature leaves, additional information is 517 required to assess the contributions of the different leaf developmental stages to the total BVOC 518 emissions for an individual leaf in the course of its lifetime. By taking into account the 
519 experimental daily methanol emission rate data from the young and mature leaves (Mozaffar et 520 al., 2017) and the cumulative methanol emissions from senescent leaves (Table 3), and by using 521 information about the relative leaf area growth rate and the duration of the young-growing 522 (encompassing young and semi-mature) and mature leaf developmental stages, it was possible to 523 estimate the cumulative methanol emissions from a $7^{\text {th }}$ leaf of a maize plant during the young524 growing, mature and senescent leaf developmental stages. The leaf number again refers to the 525 order of appearance of the leaf on the maize plant. They were $360 \pm 30 \mu \mathrm{g}, 80 \pm 30 \mu \mathrm{g}$ and $150 \pm$ $52640 \mu \mathrm{g}$, respectively, and the resulting total amount of methanol emitted by a $7^{\text {th }}$ leaf in the course 527 of its lifetime was therefore $590 \pm 60 \mu \mathrm{g}$. The young-growing, mature and senescent stages 528 consequently contributed $61 \pm 3,13 \pm 5$ and $26 \pm 6 \%$ to the total methanol emission from a $7^{\text {th }}$ 529 leaf. Details about the estimation procedure are provided in Supplement S1.

530 Based on the emission rates obtained for a $7^{\text {th }}$ leaf, the total amount of methanol emitted by all 531 leaves of a representative maize plant, grown in the environmental chamber at $25^{\circ} \mathrm{C}$ and exposed 532 to the diurnal light pattern described in Section 2.1, has been estimated for the different leaf 533 developmental stages. Values of $4.8 \pm 0.4,0.8 \pm 0.5$ and $1.9 \pm 0.6 \mathrm{mg}$ were obtained for the 534 cumulative methanol emission from all young-growing, mature, and senescent leaves over the 535 entire lifetime of the plant, respectively. The total amount of methanol emitted by the leaves of a 536 whole maize plant from shoot emergence to full senescence was therefore equal to $7.5 \pm 0.9 \mathrm{mg}$ 537 and the contributions of the different stages to the total methanol emission were $64 \pm 3,10 \pm 8$ 538 and $26 \pm 7 \%$, respectively. The estimation of the total cumulative methanol emission from a 539 whole maize plant over the course of its lifetime should however be considered with caution. As 540 already mentioned it was assumed that all leaves were exposed to the same PPFD and the effect 541 of shading by leaves with a higher leaf number was not taken into account. Moreover, a large 542 variability in the duration of the mature stage was noticed among leaves with different leaf 543 numbers, which may be related to the demands of the plant for nutrient relocation. The total leaf 544 emissions of methanol from a maize plant presented in this work could be used as a first estimate 545 for upscaling to field scale in regions characterised by environmental conditions close to those of 546 the growth chamber. However, a general upscaling from the leaf/plant level to ecosystem level 547 would definitely benefit from methanol emission measurements at different temperatures at all 548 leaf developmental stages. Moreover, uptake of atmospheric methanol by the ecosystem may 
also be important in the field (Laffineur et al., 2012; Wohlfahrt et al., 2015) and should be taken into account.

For the other BVOCs emitted by maize leaves, assumptions about the temporal evolution of the emission rates at the different leaf developmental stages are less straightforward than for methanol. Indeed, whereas methanol emission from young leaves has been associated with leaf growth (Hüve et al. 2007), this is not the case for other BVOCs and therefore a simple relationship between the daily emission rate of those compounds and the daily relative leaf area growth rate (eq. S3 in Supplement S1) cannot be put forward. Consequently, an estimation of the relative contribution of the different leaf developmental stages to the total emission from a $7^{\text {th }}$ maize leaf for other BVOCs than methanol- from the emission rate data obtained in this work would have been prone to very large errors and has therefore not been accomplished. The same applies to extrapolation to an entire maize plant.

\section{Conclusions}

Maize is one of the most cultivated crop species worldwide, but only 5 studies on BVOC exchanges from maize are available in the literature and none of them deal with emissions from senescent leaves. In contrast to most studies on BVOC emissions from artificially senescing leaves (cutting and drying), the senescent maize leaves in our experiments were still attached to the stems.

The main emitted compounds, ranked according to their cumulative emissions over the senescence period, were found to be methanol, acetic acid, acetaldehyde, hexenals, $\mathrm{m} / \mathrm{z} 59$ compounds, m/z 69 compounds, m/z 73 compounds, and m/z 83 compounds. Important differences were observed in the temporal emission profiles of these compounds. Whereas methanol, acetaldehyde, and GLVs (hexenals and m/z 83 compounds) were emitted mainly during the degeneration phase of leaf senescence, $\mathrm{m} / \mathrm{z} 59$ compounds and acetic acid emission rates increased at the end of that phase and their emissions remained high during the termination phase, even when the leaves were already completely dry. Beside m/z 59 compounds and acetic acid, the rest of the abovementioned compounds were also emitted in small but significant amounts from dry leaves during the termination phase. Therefore, not only the yellow senescent maize leaves but also the dry brown leaves, which remain attached to the plant, are an important 
source of BVOCs. By comparing cumulative BVOC emissions from senescent maize leaves with those of artificially senescing species of the Poaceae family, it was found that maize leaves were clearly among the strongest emitting species during that leaf developmental stage. Nevertheless, an improved comparison of cumulative BVOC emissions among senescent species of the Poaceae family might benefit from additional measurements on naturally senescing plants instead of results obtained from cutting and drying experiments.

Whereas senescent leaves showed a large diversity of emitted compounds, BVOC emission rates for young, semi-mature, and mature leaves were limited to methanol, $\mathrm{m} / \mathrm{z} 59$ and $\mathrm{m} / \mathrm{z} 73$ compounds, and monoterpenes. Methanol was clearly the highest emitted compound for all stages and showed a strong variation in intensity and diurnal emission patterns among the different leaf developmental stages. The contributions from the young-growing, mature, and senescent stages to the total methanol emission from a typical leaf of a maize plant were estimated to be 61,13 , and $26 \%$, respectively.

Although our growth chamber study provided new information on the contribution of senescence and other leaf developmental stages to the BVOC emissions from maize, additional studies, preferably in field conditions and at a wide variety of meteorological conditions, are definitely required to better constrain BVOC emissions for this important $\mathrm{C} 4$ crop species for use in regional and global atmospheric chemistry and climate models.

\section{Acknowledgements}

We gratefully acknowledge the financial support provided by FNRS (Fonds National de la Recherche Scientifique) for funding the CROSTVOC research project (T.0086.13), in the framework of which this study was carried out. We are also very grateful for the indispensable technical support provided by the employees of the Belgian Institute for Space Aeronomy and the University of Liège, Gembloux Agro-Bio Tech. 


\section{References}

604

605

606

607

608

609

610

611

612

613

614

615

616

617

618

619

620

621

622

623

624

625

626

627

Atkinson, R.: Atmospheric chemistry of VOCs and NOx, Atmospheric Environment, 34(12-14), 2063-2101, doi: 10.1016/S1352-2310(99)00460-4, 2000.

Aalto, J., Kolari, P., Hari, P., Kerminen, V.-M., Schiestl-Aalto, P., Aaltonen, H., Levula, J., Siivola, E., Kulmala, M. and Bäck, J.: New foliage growth is a significant, unaccounted source for volatiles in boreal evergreen forests, Biogeosciences, 11, 1331-1344, doi:10.5194/bg-11-1331-2014, 2014.

Bachy, A., Aubinet, M., Schoon, N., Amelynck, C., Bodson, B., Moureaux, C. and Heinesch, B.: Are BVOC exchanges in agricultural ecosystems overestimated? Insights from fluxes measured in a maize field over a whole growing season, Atmospheric Chemistry and Physics, 16, 5343-5356, doi: 10.5194/acp-16-5434-2016, 2016.

Bracho-Nunez, A., Welter, S., Staudt, M. and Kesselmeier, J.: Plant-specific volatile organic compound emission rates from young and mature leaves of Mediterranean vegetation, Journal of Geophysical Research, 116(D16), doi: 10.1029/2010JD015521, 2011.

Castaldo, D., Laratta, B., Loiudice, R., Giovane, A., Quagliuolo, L., and Servillo, L.: Presence of residual pectin methylesterase activity in thermally stabilized industrial fruit preparations, LWT - Food Science and Technology, 30, 479-484, doi: 10.1006/fstl.1996.0211, 1997.

Crespo, E., Graus, M., Gilman, J. B., Lerner, B. M., Fall, R., Harren, F. J. M. and Warneke, C.: Volatile organic compound emissions from elephant grass and bamboo cultivars used as potential bioethanol crop, Atmospheric Environment, 65, 61-68, doi: 10.1016/j.atmosenv.2012.10.009, 2013.

Das, M., Kang, D., Aneja, V.P., Lonneman, W., Cook, D.R. and Wesely, M.L.: Measurements of hydrocarbon air-surface exchange rates over maize, Atmospheric Environment 37(16), 2269-2277, doi: 10.1016/S1352-2310(03)00076-1, 2003. 
de Gouw, J. D., Howard, C. J., Custer, T. G. and Fall, R.: Emissions of volatile organic compounds from cut grass and clover are enhanced during the drying process, Geophysical Research Letters, 26(7), 811-814, doi: 10.1029/1999GL900076, 1999.

de Gouw, J. D., Howard, C. J., Custer, T. G., Baker, B. M. and Fall, R.: Proton-Transfer Chemical-Ionization Mass Spectrometry allows real-time analysis of volatile organic compounds released from cutting and drying of crops, Environmental Science \& Technology, 34(12), 2640-2648, doi: 10.1021/es991219k, 2000.

Eller, A.S.D., Sekimoto, K., Gilman, J.B., Kuster, W.C., de Gouw, J.A., Monson, R.K., Graus, M., Crespo, E., Warneke, C. and Fall. R.: Volatile organic compound emissions from switchgrass cultivars used as biofuel crops, Atmospheric Environment 45 (19), 3333-3337, doi: 10.1016/j.atmosenv.2011.03.042, 2011.

Ellis, A. M. and Mayhew, C. A.: Proton transfer reaction mass spectrometry: principles and applications, Wiley, Chichester, 2013.

Fechter, J.-O., Englund, F. and Lundin, A.: Association between temperature, relative humidity and concentration of volatile organic compounds from wooden furniture in a model room, Wood Material Science and Engineering 1 (2), 69-75, doi: 10.1080/17480270600900551, 2006.

Fall, R.: Abundant oxygenates in the atmosphere: a biochemical perspective, Chemical Reviews, 103(12), 4941-4952, doi: 10.1021/cr0206521, 2003.

Fall, R. and Benson, A.A.: Leaf methanol - the simplest natural product from plants, Trends in Plant Science, 1, 296-301, doi: 10.1016/S1360-1385(96)88175-0, 1996.

Fall, R., Karl, T., Hansel, A., Jordan, A. and Lindinger, W.: Volatile organic compounds emitted after leaf wounding: On-line analysis by proton-transfer-reaction mass spectrometry, Journal of Geophysical Research: Atmospheres, 104(D13), 15963-15974, doi: 10.1029/1999JD900144, 1999.

Fall, R., Karl, T., Jordan, A. and Lindinger, W.: Biogenic C5 VOCs: release from leaves after freeze-thaw wounding and occurrence in air at a high mountain observatory, Atmospheric Environment, 35(22), 3905-3916, doi: 10.1016/S1352-2310(01)00141-8, 2001. 
656

657

658

659

660

661

662

663

664

665

666

667

668

669

670

671

672

673

674

675

676

677

678

679

680

681

682

Folkers, A., Hüve, K., Ammann, C., Dindorf, T., Kesselmeier, J., Kleist, E., Kuhn, U., Uerlings, R. and Wildt, J.: Methanol emissions from deciduous tree species: dependence on temperature and light intensity, Plant Biology, 10, 65-75, doi: 10.1111/j.14388677.2007.00012.x, 2008.

Galbally, I. E. and Kirstine, W.: The production of methanol by flowering plants and the global cycle of methanol, Journal of Atmospheric Chemistry, 43, 195-229, doi: 10.1023/A:1020684815474, 2002.

Gan, S. and Amasino, R. M.: Making sense of senescence (molecular genetic regulation and manipulation of leaf senescence), Plant Physiology, 113(2), 313-319, 1997.

Graus, M., Eller, A., Fall, R., Yuan, B., Qian, Y., Westra, P., de Gouw, J. and Warneke, C.: Biosphere-atmosphere exchange of volatile organic compounds over C4 biofuel crops, Atmospheric Environment, 66, 161-168, doi: 10.1016/j.atmosenv.2011.12.042, 2013.

Guenther, A. B., Jiang, X., Heald, C., Sakulyanontvittaya, T., Duhl, T., Emmons, L. K. and Wang, X., The Model of Emissions of Gases and Aerosols from Nature version 2.1 (MEGAN 2.1): an extended and updated framework for modelling biogenic emissions, Geoscientific Model Development, 5, 1471-1492, doi: 10.5194/gmd-5-1471-2012, 2012.

Harley, P., Greenberg, J., Niinemets, Ü. and Guenther, A.: Environmental controls over methanol emission from leaves, Biogeosciences, 4, 1083-1099, doi: 10.5194/bg-4-1083-2007, 2007.

Hatanaka, A.: The biogeneration of green odour by green leaves, Phytochemistry, 34, 1201-1218, doi: 10.1016/0031-9422(91)80003-J, 1993.

Holopainen, J. K., Heijari, J., Oksanen, E. and Alessio, G. A.: Leaf volatile emissions of betula pendula during autumn coloration and leaf fall. Journal of Chemical Ecology, 36(10), 1068-1075, doi: 10.1007/s10886-010-9857-4, 2010.

Holopainen, J. K., and Gershenzon, J., Multiple stress factors and the emission of plant VOCs, Trends in Plant Science, 15, 176-184, doi: 10.1016/j.tplants.2010.01.006, 2010.

Hüve, K., Christ, M. M., Kleist, E., Uerlings, R., Niinemets, U., Walter, A. and Wildt, J.: Simultaneous growth and emission measurements demonstrate an interactive control of 
methanol release by leaf expansion and stomata, Journal of Experimental Botany, 58, 1783-1793,doi: 10.1093/jxb/erm038, 2007.

Ikan, R., Rubinszialn, Y., Nissenbaum, A. and Kaplan, I. R.: The maillard reaction: consequences for the chemical and life sciences, edited by Ikan, R., 1-25, John Wiley, New York, 1996.

Inomata, S. and Tanimoto, H.: A quantitative examination of the detection sensitivities of protontransfer reaction mass spectrometry for gaseous 2-propanol and acetic acid, Bulletin of the Chemical Society of Japan, 83, 900-904, doi: 10.1246/bcsj.20100043, 2010.

Jardine, K., Karl, T., Lerdau, M., Harley, P., Guenther, A., and Mak, J.E.: Carbon isotope analysis of acetaldehyde emitted from leaves following mechanical stress and anoxia, Plant Biology, 11(4), 591-597, doi: 10.1111/j.1438-8677.2008.00155.x, 2009.

Karl, T., Fall, R., Jordan, A. and Lindinger, W.: On-line analysis of reactive VOCs from urban lawn mowing, Environmental Science \& Technology, 35(14), 2926-2931, doi: 10.1021/es010637y, 2001a.

Karl, T., Guenther, A., Jordan, A., Fall, R. and Lindinger, W.: Eddy covariance measurement of biogenic oxygenated VOC emissions from hay harvesting, Atmospheric Environment, 35, 491-495, doi: 10.1016/S1352-2310(00)00405-2, $2001 \mathrm{~b}$.

Karl, T., Guenther, A., Lindinger, C., Jordan, A., Fall, R. and Lindinger, W.: Eddy covariance measurements of oxygenated volatile organic compound fluxes from crop harvesting using a redesigned proton-transfer-reaction mass spectrometer, Journal of Geophysical Research: Atmospheres, 106(D20), 24157-24167, 2001c.

Karl, T., Harren, F., Warneke, C., Gouw, J. D., Grayless, C. and Fall, R.: Senescing grass crops as regional sources of reactive volatile organic compounds. Journal of Geophysical Research, 110(D15), doi: 10.1029/2005JD005777, 2005.

Keskitalo, J., Bergquist, G., Gardeström, P. and Jansson, S.: A cellular timetable of autumn senescence, Plant Physiology, 139(4), 1635-1648, doi: 10.1104/pp.105.066845, 2005.

Kesselmeier, J., Bode, K., Gerlach, C., and Hork, E.-M.: Exchange of atmospheric formic and acetic acids with trees and crop plants under controlled chamber and purified air 
conditions, Atmospheric Environment, 32(10), 1765-1775, doi: 10.1016/S13522310(97)00465-2, 1998.

Kreuzwieser, J., Kuhnemann, F., Martis, A., Rennenberg, H. and Urban, W.: Diurnal pattern of acetaldehyde emission by flooded poplar trees, Physiologia Plantarum, 108(1), 79-86, doi: 10.1034/j.1399-3054.2000.108001079.x, 2000.

Kuhn, U., Rottenberger, S., Biesenthal, T., Wolf, A., Schebeske, G.,Ciccioli, P., Brancaleoni, E., Frattoni, M., Tavares, T. M. and Kesselmeier, J.: Isoprene and monoterpene emissions of Amazonian tree species during the wet season: direct and indirect investigations on controlling environmental functions, Journal of Geophysical Research: Atmosphere, 107 (D20), LBA 38-1-LBA 38-13, doi: 10.1029/2001JD000978, 2002.

Laffineur, Q., Aubinet, M., Schoon, N., Amelynck, C., Müller, J.-F., Dewulf, J., Van Langenhove, H., Steppe, K., and Heinesch, B.: Abiotic and biotic control of methanol exchanges in a temperate mixed forest, Atmospheric Chemistry and Physics, 12, 577-590, doi: 10.5194/acp-12-577-2012, 2012.

Laothawornkitkul, J., Taylor, J. E., Paul, N.D., Hewitt, C.N.: Biogenic volatile organic compounds in the Earth system, New Phytologist, 183, 27-51, 2009.

Lim, P. O., Kim, H. J. and Nam, H. G.: Leaf senescence, Annual Review of Plant Biology, 58, 115-136, doi: 10.1146/annurev.arplant.57.032905.105316, 2007.

Lindinger, W., Hansel, A., Jordan, A.: On-line monitoring of volatile organic compounds at pptv levels by means of proton-transfer-reaction mass-spectrometry (PTR-MS) - medical applications, food control and environmental research, International Journal of Mass Spectrometry and Ion Processes, 173(3), 191-241, 1998.

MacDonald, R.C. and Fall, R.: Detection of substantial emissions of methanol from plants to the atmosphere, Atmospheric Environment, Part A General Topics, 27, 1709-1713, doi: 10.1016/0960-1686(93)90233-O, 1993.

Mozaffar, A., Schoon, N., Digrado, A., Bachy, A., Delaplace P., du Jardin, P., Fauconnier, M.-L., Aubinet, M., Heinesch, B. and Amelynck, C.: Methanol emissions from maize: ontogenetic dependence to varying light conditions and guttation as an additional factor constraining 

the flux, Atmospheric Environment, 43, 405-417, doi: 10.1016/j.atmosenv.2016.12.041, 2017.

Nemecek-Marshall, M., MacDonald, R. C., Franzen, J. J., Wojciechowski, C. L. and Fall, R.: Enzymatic detection of gas-phase methanol and relation of methanol fluxes to stomatal conductance and leaf development, Plant Physiology, 108, 1359-1368, 1995.

Ozuna, R., Yera, R., Ortega, K., and Tallman, G.: Analysis of Guard Cell Viability and Action in Senescing Leaves of Nicotiana glauca (Graham), Tree Tobacco, Plant Physiology, 79, 7$10,1985$.

Pacifico, F., Harrison, S. P., Jones, C. D., and Sitch, S.: Isoprene emissions and climate, Atmospheric Environment, 43, 6121-6135, doi: 10.1016/j.atmosenv.2009.09.002, 2009.

Pang, X.: Biogenic volatile organic compound analyses by PTR-TOF-MS: Calibration, humidity effect and reduced electric field dependency, Journal of Environmental Sciences, 32, 196206, doi: 10.1016/j.jes.2015.01.013, 2015.

Pierik, R., Ballaré, C. L., and Dicke, M.: Ecology of plant volatiles: taking a plant community perspective, Plant, Cell and Environment, 37, 1845-1853, doi: 10.1111/pce.12330, 2014.

Prochazkova, D., Sairam, R.K., Srivastava, G.C., and Singh, D.V.: Oxidative stress and antioxidant activity as the basis of senescence in maize leaves, Plant Science, 161(4), 765771, doi: 10.1016/S0168-9452(01)00462-9, 2001.

Rottenberger, S., Kuhn, U., Wolf, A., Schebeske, G., Oliva, S. T., Tavares, T. M. and Kesselmeier, J.: Exchange of short-chain aldehydes between Amazonian vegetation and the atmosphere. Ecological Applications, 14, 247-262, doi: 10.1890/01-6027, 2004.

Scala, A., Allmann, S., Mirabella, R., Haring, M. and Schuurink, R.: Green Leaf Volatiles: A plant's multifunctional weapon against herbivores and pathogens, International Journal of Molecular Sciences, 14(9), 17781-17811, doi: 10.3390/ijms140917781, 2013.

Schade, G. W. and Goldstein, A. H.: Fluxes of oxygenated volatile organic compounds from a ponderosa pine plantation, Journal of Geophysical Research, 106, 3111-3123, doi: 10.1029/2000JD900592, 2001. 
Schaeffer, V.H., Bhoosan, B., Chen, S., Sonenthal, J.S. and Hodgson, A.J.: Characterisation of volatile organic chemical emissions from carpet cushions, Journal of the Air and Waste Management Association, 46(9), 813-820, doi: 10.1080/10473289.1996.10467516, 1996.

Schwarz, K., Filipiak, W., and Amann, A.: Determining concentration patterns of volatile compounds in exhaled breath by PTR-MS, Journal of Breath Research, 3, 027002, doi: 10.1088/1752-7155/3/2/027002, 2009.

Springer, A., Kang, C., Rustgi, S., von Wettstein, D., Reinbothe, C., Pollmann, S. and Reinbothe, S.: Programmed chloroplast destruction during leaf senescence involves 13lipoxygenase (13-LOX), Proceedings of the National Academy of Sciences, vol. 113(12), 3383-3388, 2016.

Steckel, V., Knöpfle A. and Ohlmeyer, M.: Effects of climatic test parameters on acetic acid emission from beech, Holzforschung, 67, 47-51, doi: 10.1515/hf-2011-0237, 2013.

Su, T.: Parametrization of kinetic energy dependences of ion-polar molecule collision rate constants by trajectory calculation. Journal of Chemical Physics, 100, 4703, doi: 10.1063/1.466255, 1994.

Takahashi, Y., Tsubaki, S., Sakamoto, M., Watanabe, S., and Azuma, J.: Growth-dependent chemical and mechanical properties of cuticular membranes from leaves of Sonneratia alba, Plant, Cell and Environment, 35, 1201-1210, doi: 10.1111/j.1365-3040.2012.02482.x, 2012.

Taiz, L., Zeiger, E., Moller, I.M., and Murphy, A.: Plant physiology and development, $6^{\text {th }}$ edition, Sinauer Associates, Sunderland, CT, 2015.

Tani, A., Hayward, S., and Hewitt, C.N.: Measurement of monoterpenes and related compounds by proton transfer reaction-mass spectrometry, International Journal of Mass Spectrometry, 223/22, 561-578, doi: 10.1016/S1387-3806(02)00880-1, 2003.

Warneke, C., Karl, T., Judmaier, H., Hansel, A., Jordan, A., Lindinger, W. and Crutzen, P. J.: Acetone+propanal, methanol, and other partially oxidized volatile organic emissions from dead plant matter by abiological processes: Significance for atmospheric HOx chemistry, Global Biogeochemical Cycles, 13(1), 9-17, 1999. 
809 

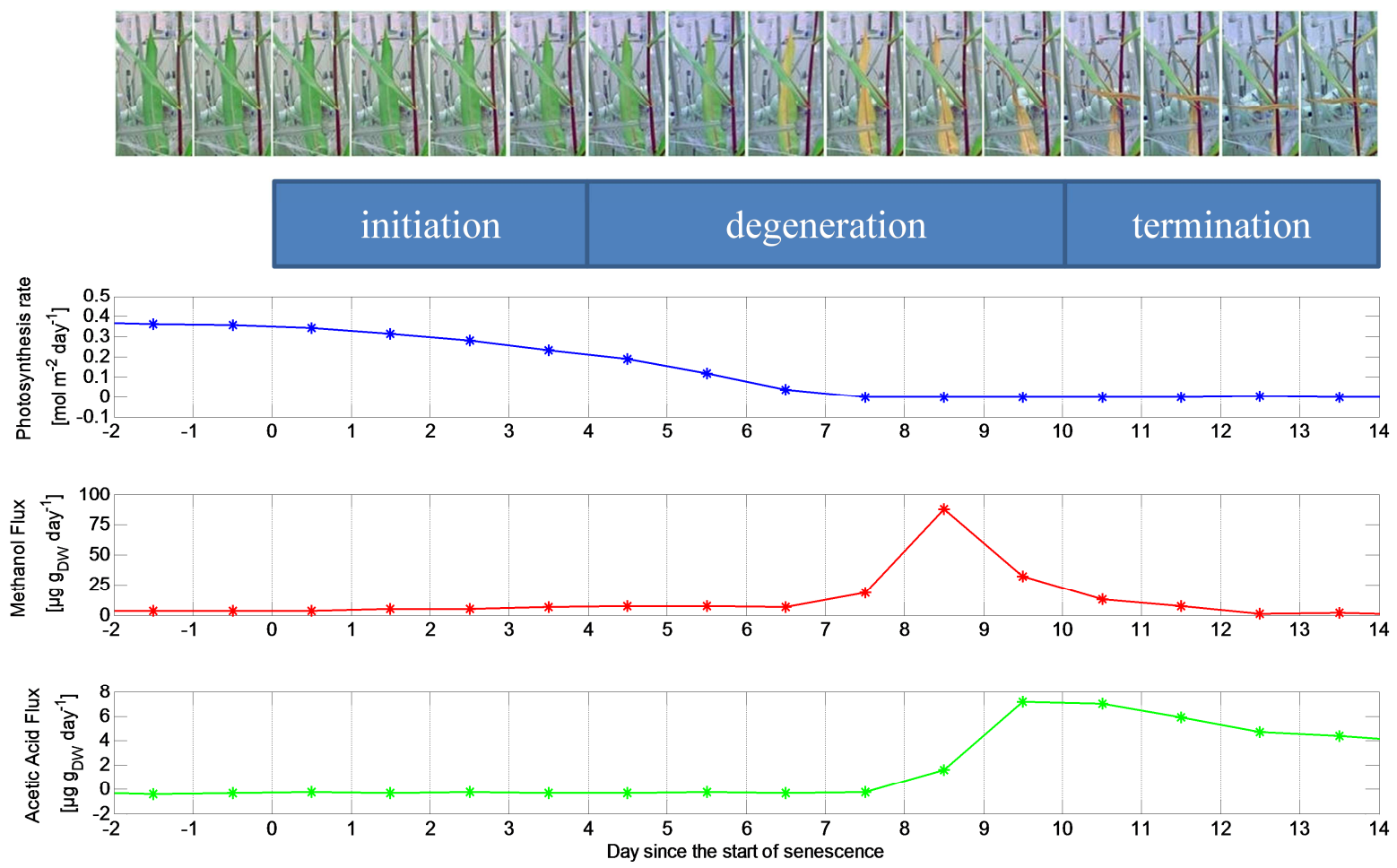

821

822

823

824

825

826 
Figure 2

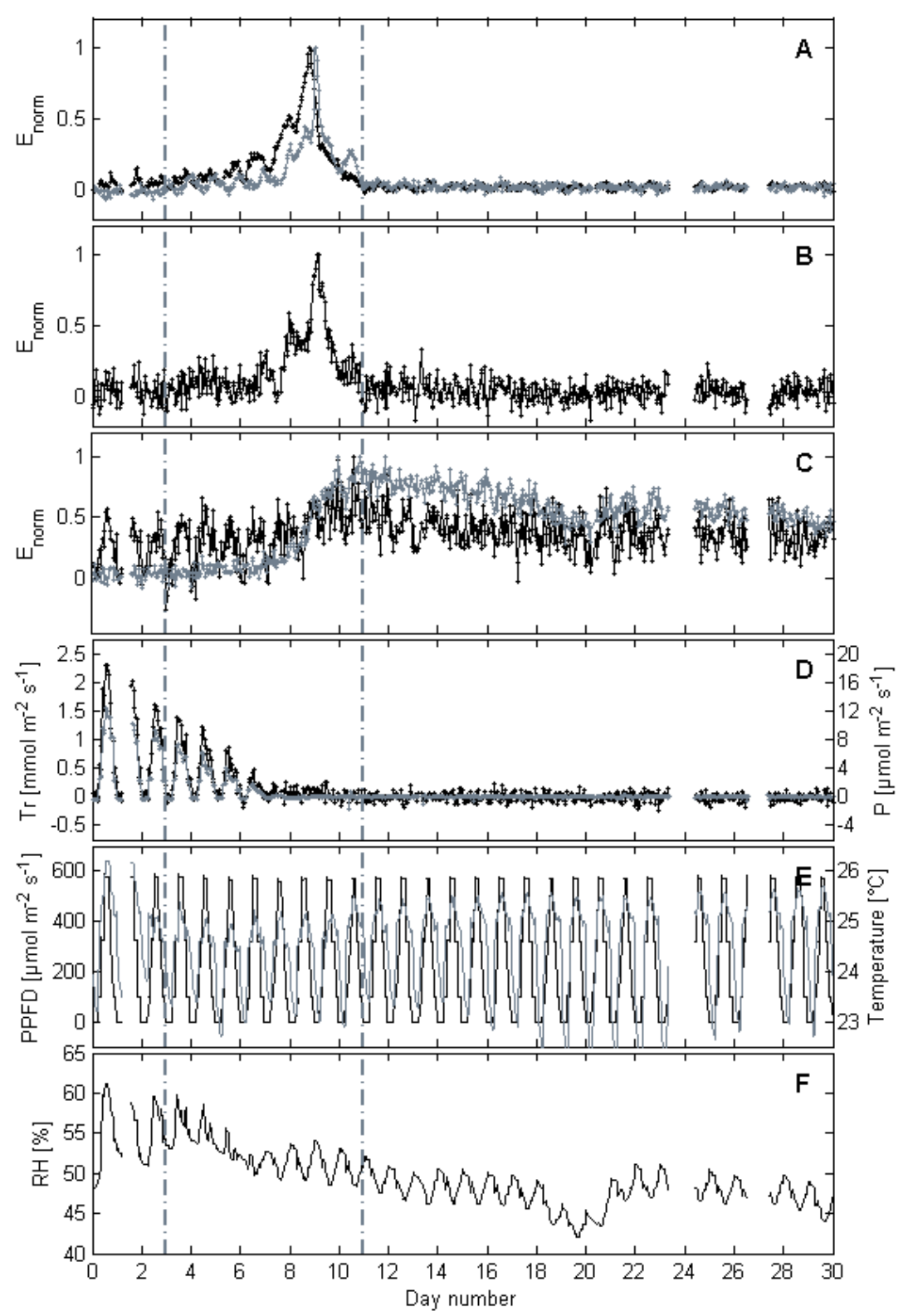




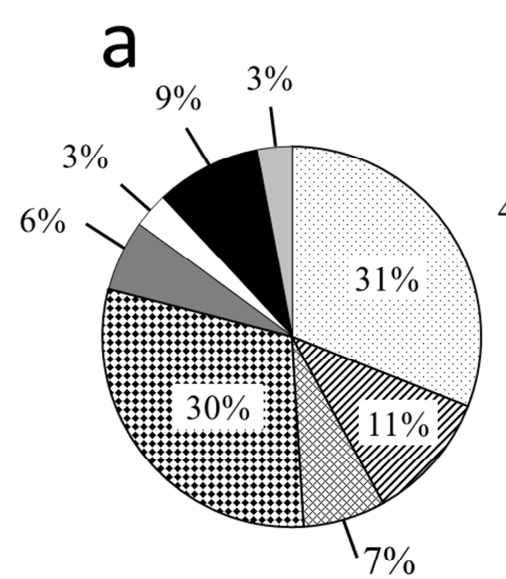

$\square$ methanol 图 $\mathrm{m} / \mathrm{z} 59$ compounds $\square \mathrm{m} / \mathrm{z} 69$ compounds

- hexenals b c

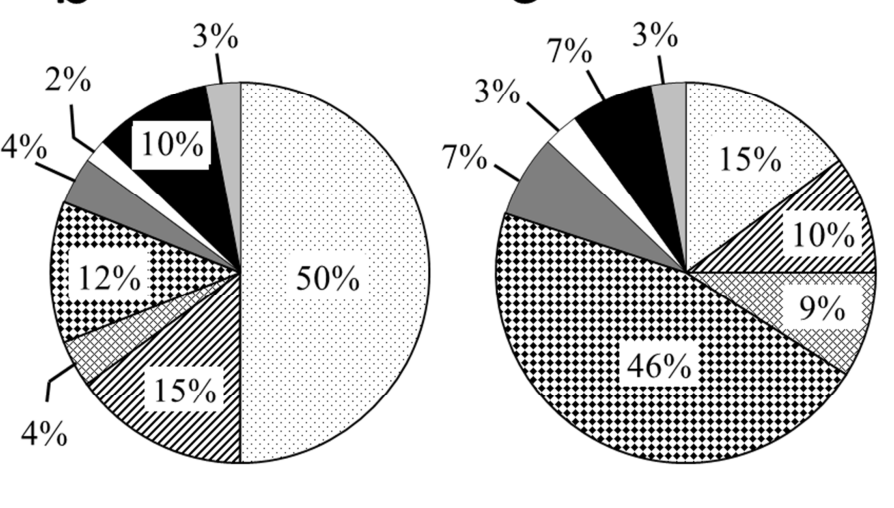

834

835

836

837

838

839

840

841 


\section{Figure captions}

844 Fig. 1: Temporal evolution of the daily photosynthesis rate and the daily emission rates of 845 methanol and acetic acid for a specific senescent leaf and corresponding pictures of the leaf taken 846 daily at 10 AM. The different phases of developmental leaf senescence are indicated.

848 Fig. 2: Normalised instantaneous emission rates of methanol (A, black dots), acetaldehyde (A, 849 grey dots), hexenals (B), m/z 59 compounds (C, black dots), and acetic acid (C, grey dots) from a 850 senescent maize leaf since the onset of senescence, together with the transpiration rate (Tr) (D, 851 black dots), the photosynthesis rate (P) (D, grey dots), light (PPFD) (E, black line), temperature 852 (T) (E, grey line) and relative humidity (RH) (F) conditions in the enclosure. The BVOC 853 emission rates have been normalised with respect to their maximum value to facilitate the 854 comparison of temporal emission profiles for the different compounds. The dot-dashed vertical 855 grey lines indicate the start of the degradation (day 3) and termination (day 11) phase of 856 senescence, respectively. Gaps in the data are due to instrument failure.

857

858 Fig. 3: Proportion of cumulative BVOC emissions from the senescent leaves for different 859 periods: (a) from the onset of leaf senescence to the end of the investigations, (b) during the leaf 860 chlorosis period (degeneration phase), (c) from the end of the chlorosis period to the end of the 861 measurements (termination phase). Cumulative emissions were averaged over 10 replicates and 862 only compounds which individually made up over $0.5 \%$ of the total BVOC emission were 863 considered. Total cumulative BVOC emissions for $\mathrm{a}, \mathrm{b}$ and $\mathrm{c}$ were $0.67 \pm 0.11,0.33 \pm 0.04$ and $8640.34 \pm 0.08 \mathrm{mg} / \mathrm{g}_{\mathrm{DW}}{ }^{-1}$, respectively. 